\title{
Digital technology in orthognathic surgery: virtual surgical planning and digital transfer
}

\author{
Ju-Hong Jeon, D.D.S., M.D. \\ Section Editor of JKAOMS \\ Department of Oral and Maxillofacial Surgery, Asan Medical Center, Seoul, Korea
}

Orthognathic surgical planning is sophisticated and timeconsuming. Traditionally, cephalometric and/or clinical surgical planning has been used, and most surgeons have chosen model surgery and handmade acrylic occlusal splints as its transfer method. Surgical treatment objective (STO), which was established by Wolford et al. ${ }^{1}$ in 1985 , is one of the most widely used traditional surgical planning methods.

Since the invention of computed tomography (CT) by Godfrey Hounsfield in 1971 and three-dimensional (3D) printing by Chuck Hull in 1983, the digital environment has been enhanced tremendously. Dental cone-beam computed tomography $(\mathrm{CBCT})$ is arguably the most important advancement in oral and maxillofacial radiology ${ }^{2}$. Currently, patient CBCT scans and scanned images of patient dental casts can be registered (superimposed) using various software programs. The result is a $3 \mathrm{D}$ computerized composite image of the skull, including occlusion, which is the basis of virtual planning of orthognathic surgery. Direct digital manufacturing techniques, which is subtracting or additive one, can enable transfer of the virtual plan to the operating room using surgical guides and splints, customized plates, and prostheses.

Virtual surgical planning (VSP) or computer-aided surgical simulation (CASS) in orthognathic surgery facilitates diagnosis, treatment planning, and evaluation of treatment outcomes of dentofacial deformities and is essential for digital transfer methods such as computer-aided designed and manufactured

\section{Ju-Hong Jeon}

Department of Oral and Maxillofacial Surgery, Asan Medical Center, 88 Olympic-ro 43-gil, Songpa-gu, Seoul 05505, Korea

TEL: +82-2-3010-3958 FAX: +82-2-3010-6967

E-mail:mfsjih@unitel.co.kr

ORCID: https://orcid.org/0000-0003-4730-1102

(c) This is an open-access article distributed under the terms of the Creative Commons Attribution Non-Commercial License (http://creativecommons.org/ licenses/by-nc/4.0/), which permits unrestricted non-commercial use, distribution, and reproduction in any medium, provided the original work is properly cited. Copyright (C) 2019 The Korean Association of Oral and Maxillofacial Surgeons. All rights reserved.
(CAD/CAM) splints, customized miniplates with cutting and drilling guides, and navigation ${ }^{3}$. This paradigm shift in orthognathic surgery started in the early 2000s with Gwen Swennen, Jaime Gateno, and James Xia, independently ${ }^{4,5}$.

Currently, most surgeons still use conventional surgical planning methods, such as clinical examination, facebow transfer and plaster model surgery, to fabricate intermediate and final occlusal wafers for double jaw surgery. VSP enables creation of multiple simulations without altering the initial model, and may also provide the clinician with illustrative images that can be shared with the patient. However, VSP is time-consuming for the preparation and requires expensive hardware and software. There are also difficulties managing dental occlusion and soft tissue simulations. VSP is not an alternative to traditional methods, but can be a useful tool to manage the most challenging cases, such as facial asymmetry and multi-dimensional deformities. Recently, a newly developed CASS program with digital transfer using customized osteotomy guides and customized miniplates has been launched in Korea; it has yielded promising results, especially in facial asymmetry cases ${ }^{6,7}$. Several other CASS programs for orthognathic surgery are being developed. It is likely that the shortcomings of VSP will be overcome in the near future to great benefit in Korea.

\section{Conflict of Interest}

No potential conflict of interest relevant to this article was reported.

\section{References}

1. Wolford LM, Hilliard FW, Dugan DJ. Surgical treatment objective: a systematic approach to the prediction tracing. St. Louis: C.V. Mosby; 1985.

2. Masri R, Driscoll CF. Clinical applications of digital dental technology. Ames: Wiley-Blackwell; 2015. 
3. Pascal E, Majoufre C, Bondaz M, Courtemanche A, Berger M, Bouletreau P. Current status of surgical planning and transfer methods in orthognathic surgery. J Stomatol Oral Maxillofac Surg 2018;119:245-8.

4. Bell RB. A history of orthognathic surgery in North America. J Oral Maxillofac Surg 2018;76:2466-81.

5. Zinser MJ, Sailer HF, Ritter L, Braumann B, Maegele M, Zöller JE. A paradigm shift in orthognathic surgery? A comparison of navigation, computer-aided designed/computer-aided manufactured splints, and "classic" intermaxillary splints to surgical transfer of virtual orthognathic planning. J Oral Maxillofac Surg 2013;71:2151.e1-21.

6. Kim JW, Kim JC, Jeong CG, Cheon KJ, Cho SW, Park IY, et al. The accuracy and stability of the maxillary position after orthognathic surgery using a novel computer-aided surgical simulation system. BMC Oral Health 2019;19:18.

7. Kim JW, Kim JC, Cheon KJ, Cho SW, Kim YH, Yang BE. Computer-aided surgical simulation for yaw control of the mandibular condyle and its actual application to orthognathic surgery: a one-year follow-up study. Int J Environ Res Public Health 2018;15:E2380.

How to cite this article: Jeon JH. Digital technology in orthognathic surgery: virtual surgical planning and digital transfer. J Korean Assoc Oral Maxillofac Surg 2019;45:231-232. https://doi. org/10.5125/jkaoms.2019.45.5.231 